Casos Clínicos

Arch. Esp. Urol., 61, 4 (534-536), 2008

\section{METÁSTASIS OVÁRICA DE CARCINOMA DE CÉLULAS RENALES PRIMARIO}

\author{
Antonio Jalón Monzón, Miguel Álvarez Múgica, \\ Verónica Bulnes Vázquez', Roberto Carlos González \\ Álvarez, Jorge García Rodríguez, José Luis Martín \\ Benito, Javier Ferrer Barriendo² y Francisco Javier \\ Regadera Sejas.
}

Servicio de Urología 1, Servicio de Radiodiagnóstico $1^{1}$ y Servicio de Ginecología-Obstetricia ${ }^{2}$. Hospital Universitario Central de Asturias. Oviedo. Asturias. España.

Resumen.- OBJETIVO: Presentar un caso de metástasis ovárica secundaria a un carcinoma de células claras renal.

MÉTODO/RESULTADOS: Mujer de 52 años que consultó por metrorragias siendo inicialmente diagnosticada de carcinoma primario de ovario. En los estudios de extensión se informa de masa renal sugestiva de metástasis ovárica. La intervención quirúrgica consistió en histerectomía con doble anexectomía y nefrectomía radical. El diagnóstico final fue de carcinoma de células claras renal con metástasis ovárica.
CONCLUSIÓN: Las metástasis tumorales en el ovario presentan un problema diagnóstico en su interpretación, especialmente cuando las metástasis presentan una histología similar al primario de ovario. Debido a las implicaciones terapéuticas y pronósticas es muy importante diferenciar si se trata de un tumor ovárico primario o un metástasis de un carcinoma renal.

Palabras clave: Metástasis ovárica. Carcinoma renal.

Summary.- OBJECTIVE: We report one case of ovarian metastasis secondary to a renal clear cell carcinoma.

METHODS/RESULTS: 52-year-old consulting for metrorrhagia with the initial diagnosis of primary ovarian carcinoma. Tumor dissemination work up tests reported a renal mass suggestive of ovarian metastasis. Surgery included hysterectomy, double annexectomy, and radical nephrectomy. Final diagnosis was renal clear cell carcinoma with ovarian metastasis.

CONCLUSIONS: Metastases to the ovary pose a diagnostic problem in their interpretation, especially when they show a similar histology to the primary ovarian tumor. Due to therapeutic and prognostic implications, it is very important to differentiate if it is a primary ovarian tumor or a metastasis from a renal carcinoma.

Keywords: Ovarian metastasis. Renal carcinoma.

\section{INTRODUCCIÓN}

Se estima que más de 30.000 pacientes son diagnosticados anvalmente en Estados Unidos de carcinoma de células renales (CCR) (1). Aunque los avances en procedimientos diagnósticos han conducido a una detección temprana del CCR, un tercio de los pacientes con nuevo diagnóstico presentarán enfermedad metastásica de inicio (2). Por otro lado, cerca de la mitad de los pacientes que son nefrectomizados con intención curativa, sufrirán metástasis a distancia durante el seguimiento $(1,3)$. El $70 \%$ de las metástasis están limitadas a un solo órgano, generalmente pulmón $(40 \%)$ o hueso $(22 \%)$, siendo únicas en el $2-3 \%$ de los casos (4).

Las metástasis tumorales en el ovario suponen un problema diagnóstico en su interpretación. Esto ocurre especialmente cuando las metástasis presentan una histología similar a los tumores primarios de ovario. El CCR es una de estas entidades. Aunque raramente metastatiza 
en el ovario, a menudo se confunden con tumores de células claras del ovario. Debido a las implicaciones terapéuticas y pronósticas, es muy importante diferenciar si se trata de un tumor ovárico primario o una metástasis de un CCR.

Presentamos un caso de metástasis ovárica por CCR de células claras.

\section{CASO CLÍNICO}

Mujer de 52 años de edad, con hipertensión arterial como único antecedente de interés. Consultó al Servicio de Ginecología por metrorragias acompañadas de dolor abdominal. No refería hematuria ni dolor en fosas renales. Se realizó ecografía vaginal que demostró masa anexial izquierda de $7 \mathrm{~cm}$ de diámetro mayor y muy vascularizada, con útero grande y ovario derecho de características normales. Con la sospecha de carcinoma ovárico primario se completó el estudio de estadificación con la realización de TC abdómino-pélvico, identificándose una masa compleja en polo inferior de riñón derecho, de $64 \times 65 \mathrm{~mm}$ de diámetro, con intensa captación de contraste y áreas hipodensas centrales (Figura 1). Se informó, así mismo, de otros dos pequeños nódulos de 17 y $10 \mathrm{~mm}$ dependientes del polo superior del mismo riñón de similares características que las lesiones anteriores (Figura 2). El anejo izquierdo presentaba una lesión sólido-quística de 90 x $65 \mathrm{~mm}$, con intensa captación de contraste (Figuras 3 y 4 ). No se observaron adenopatías regionales ni implantes metastásicos peritoneales.

Con la sospecha diagnóstica de carcinoma ovárico primario y metástasis renal secundaria, se practicó histerectomía total y doble anexectomía, realizándose en el mismo acto quirúrgico nefrectomía radical derecha. El

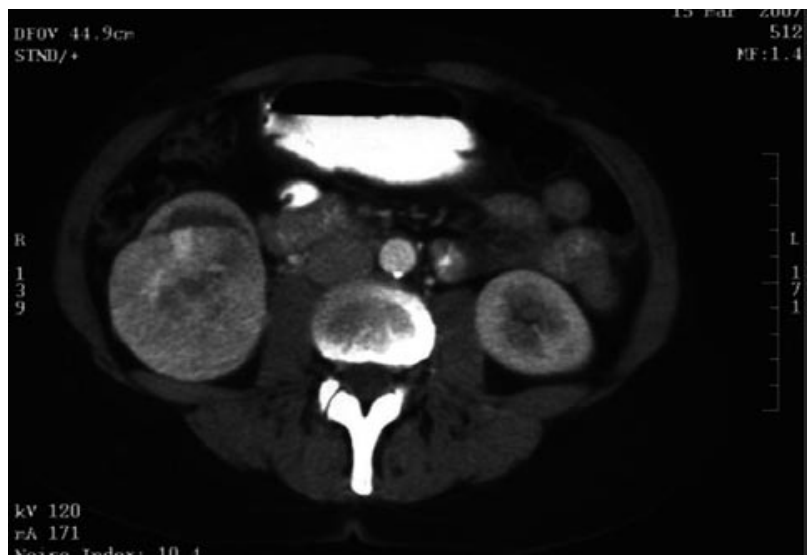

FIGURA 1. TC abdominal. Masa compleja de $65 \times 65 \mathrm{~mm}$ dependiente del polo inferior del riñón derecho. estudio histológico intraoperatorio de la estructura ovárica se informó como metástasis de carcinoma de células renales en ovario. El diagnóstico histológico renal definitivo fue de carcinoma de células renales grado I de Fuhrman extendiéndose a grasa perirrenal, sin infiltrar la vena renal.

\section{DISCUSIÓN}

Aproximadamente un $25-30 \%$ de los pacientes con CCR tienen enfermedad metastásica en el momento del diagnóstico, y hasta un $40 \%$ de los pacientes desarrollarán metástasis a distancia durante su evolución (5). Las localizaciones metastásicas más frecuentes son el pulmón, ganglios linfáticos, huesos, hígado, suprarrenales y cerebro (6). Otras localizaciones descritas con menor frecuencia son la vejiga (7), ojos (8), pene (9) y otras como etmoides, laringe, nasosinusal, bronquios, estómago, páncreas, duodeno y escroto, recogidas en una revisión del año 2005 (10).

Las metástasis ováricas de CCR es rara, habiéndose recogido en la literatura hasta el año 2006 menos de 20 casos (11). Esta rareza puede ser debida al hecho de predominar el CCR en hombres, encontrar esclerosis vascular de ovarios postmenopaúsicos en el grupo de edad donde el CCR es más común, y la dificultad en el diagnóstico diferencial entre metástasis de CCR en ovario y carcinoma de células claras primario de ovario $(11,12)$. Se cree que estas metástasis ováricas ocurren por embolización venosa retrógrada a través de la vena renal a los vasos ováricos (13).

El rango de edad descrito en las diversas publicaciones es de 46 a 66 años (con una media de 54 años). En una revisión realizada en el 2004 por Valappil y cols. (12), el tumor ovárico fue detectado antes que el primario

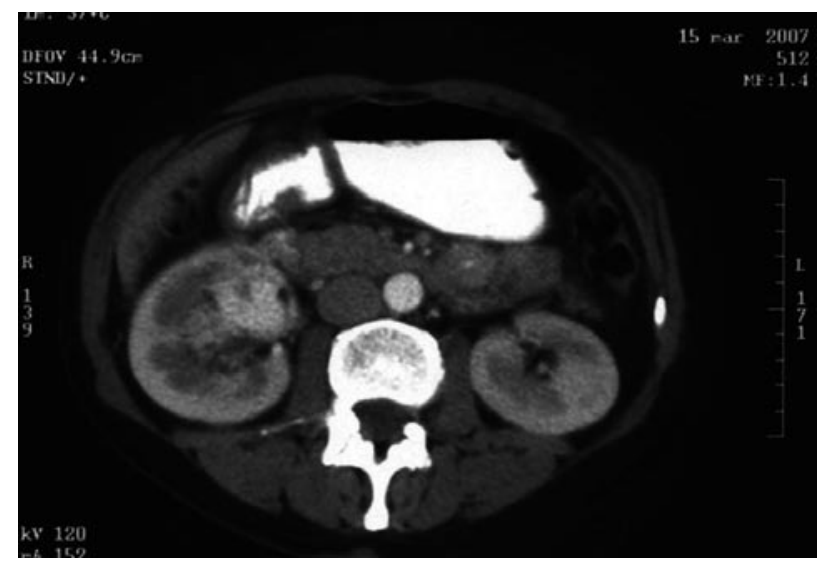

FIGURA 2. TC abdominal. Pequeños nódulos de aspecto sólido en polo superior de riñón derecho. 


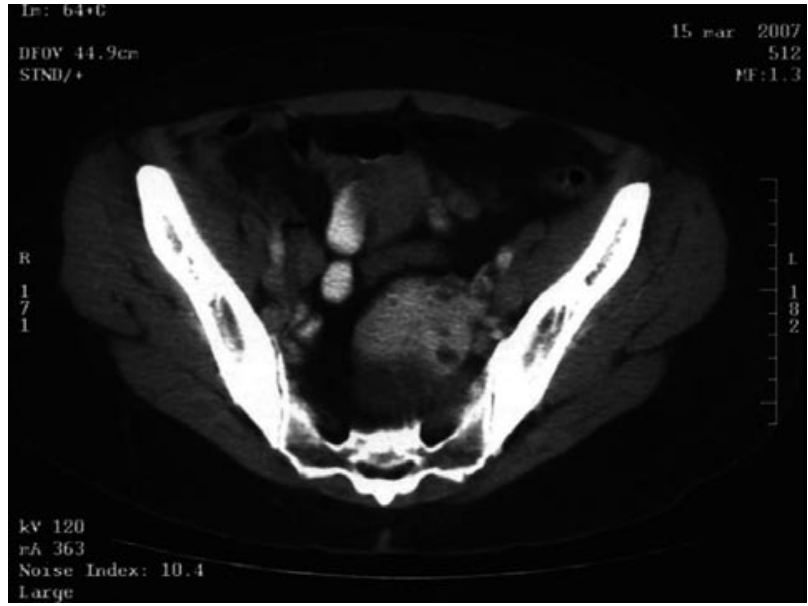

FIGURA 3. TC abdominal. Masa con componente sólido dependiente de anejo izquierdo.

renal en 5 casos, siendo en 7 restantes diagnosticado entre los 6 meses y los 14 años del tumor renal, presentándose la metástasis ovárica en 4 casos dentro de los 6 meses a 3 años después del diagnóstico del tumor renal. Al igual que el caso que exponemos, Kato y cols. describen la presentación simultánea de la masa renal y ovárica (11).

La localización del tumor renal descrita con mayor frecuencia es en el lado izquierdo, correspondiendo así mismo la lateralidad del tumor ovárico metastático (12).

La presentación clínica puede incluir síntomas derivados de la masa renal (hematuria, dolo, masa palpable en fosa renal), como de la metástasis ovárica (alteraciones menstruales, dolor pélvico, ascitis), confirmándose la sospecha clínica mediante realización de ecografía y TC abdómino-pélvico que revelará una masa renal compatible con CCR y una masa ovárica septada, sólida o sólido-quística, con márgenes irregulares (14).

Las características macroscópicas que predominan a nivel ovárico son la de un tumor sin crecimiento exofítico y áreas mixtas quísticas y sólidas amarillentas, con focos hemorrágicos. El examen microscópico suele revelar nidos de células epiteliales con patrón alveolar o tubular, con abundante citoplasma claro, núcleo pequeño y material eosinófilo intraluminal $(12,13)$.

Las metástasis del carcinoma de células renales son a menudo diagnosticadas como carcinoma de células claras primario de ovario. Sin embargo, ciertas características histológicas y ultraestructurales pueden ayudar a establecer un correcto diagnóstico. La presencia de células en tachuela y de mucina extracelular es más típica del carcinoma de células claras del ovario, mientras que la vascularización es más pronunciada en el carci-

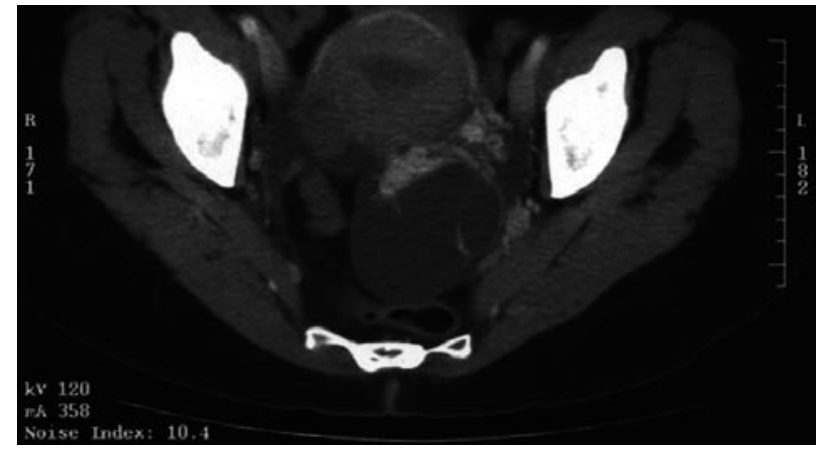

FIGURA 4. TC abdominal. Componente líquido de la masa anexial izquierda.

noma de células renales $(15,16)$. Ultraestructuralmente, los tumores renales generalmente muestran numerosas vacuolas lipídicas, largas microvellosidades delgadas, abundante glucógeno y ausencia de retículo endoplásmico rugoso (13).

Recientemente el papel de la inmunohistoquímica ha sido evaluado para diferenciar estos tumores. El RCC como marcador de célula renal, es un anticuerpo monoclonal que se expresa en el $80-90 \%$ de tumores de células renales pero su especificidad como marcador diagnóstico no ha sido todavía establecida. La citoqueratina 7, la cual es expresada por muchos adenocarcinomas de origen ovárico, es típicamente negativa en el CCR. El CA 125 es otro marcador generalmente expresado por tumores del epitelio ovárico incluyendo el carcinoma de células claras y habitualmente negativo en el CCR de células claras (16).

\section{CONCLUSIÓN}

La dificultad en el diagnóstico diferencial entre el carcinoma de células claras primario ovárico o metastático renal puede verse facilitada mediante las pruebas de imagen, la evaluación macro-microscópica de la pieza, las características ultraestructurales de la misma y la inmunohistoquímica. De esta diferenciación se derivarán las implicaciones terapéuticas y pronósticas.

\section{BIBLIOGRAFÍA y LECTURAS RECOMENDADAS ( lectura fundamental)}

1. SHETH, S.; SCATARIGE, J.C; HORTON, K.M. y cols.: "Current concepts in the diagnosis and management of renal cell carcinoma: role of multidetector CT and three-dimensional CT". Radiographics, 21: 237, 2001 . 
2. TOYODA, Y.; SHINOHARA, N.; HARABAYASHI, T. y cols.: "Survival and prognostic classification of patients with metastatic renal cell carcinoma of bone". Eur. Urol., 52: 163, 2007.

3. ZISMAN, A.; PANTUCK, A.J.; DOREY, F. y cols.: "Improved prognostication of renal cell carcinoma using integrated staging system". J. Clin. Oncol., 19: 1649, 2001.

4. WHELAN, P.: "The medical treatment of metastatic renal cell carcinoma". EUA Update Series, 1: 237, 2003.

5. SNITOH, H.: "Distant metastases of renal adenocarcinoma". Cancer, 48: 1487, 1981.

6. SUFRIN, G.: "The challenges of renal adenocarcinoma”. Surg. Clin. North Am., 62: 1101, 1982.

7. GARCÍA RODRÍGUEZ, J.; FERNÁNDEZ GÓMEZ, J.M.; JALÓN MONZÓN, A. y cols.: "Metástasis vesical de carcinoma renal". Arch. Esp. Urol., 57: 1123, 2004.

8. RODRÍGUEZ FABA, O.; MARTÍNEZ GÓMEZ, F.J.; PARRA MUNTANER, L. y cols.: "Carcinoma de células renales con metástasis pulmonar y ocular tardías". Arch. Esp. Urol., 57: 545, 2004.

9. PASCUAL MATEO, C.; NIETO GALLO, M.A.; LUJÁN GALÁN, M. y cols.: "Retención urinaria aguda y hematuria secundarias a metástasis peneana por carcinoma renal de células claras". Actas Urol. Esp., 29: 593, 2005.

10. PÉREZ FENTES, D.A.; BLANCO PARRA, M.; TORCEDO CAAMAÑO, V. y cols.: "Carcinoma renal metastático de localización atípica. Revisión de la literatura". Actas Urol. Esp., 29: 621, 2005.

11. KATO, Y.; NUMATA, A.; WADA, N. y cols.: "A case of metastatic renal cell carcinoma to the ovary". Hinyokika Kiyo, 52: 923, 2006.

**12. VALAPPIL, S.V.; TOON, P.G.; ANANDARAM, P.S.: "Ovarian metastasis from primary renal cell carcinoma: Report of a case and review of literature". Gynecol. Oncol., 94: 846, 2004.

13. YOUNG, R.H.; HART, W.R.: "Renal cell carcinoma metastatic to the ovary: A report of three cases enphasizing possible confusion with ovarian clear cell adenocarcinoma". Int. J. Gynecol. Pathol., 11: 96, 1992.

14. FIELDS, S.; LIBSON, E.; LAVIE, O. y cols.: "Renal cell carcinoma metastatic to the ovary. Ultrasound and CT appearance". Clin. Imaging, 20: 42, 1996.

15. VARA, A.; MADRIGAL, B.; VEIGA, M. y cols.: "Bilateral ovarian metastasic from renal cell carcinoma". Acta oncol., 37: 379, 1998.

**16. HAMMOCK, L.; GHORAB, Z.; GÓMEZ-FERNÁNDEZ, C.R.: "Metastatic renal cell carcinoma to the avary: A case report and discussion of differential diagnoses". Arch. Pathol. Lab. Med., 127: 123, 2003.
Casos Clínicos

Arch. Esp. Urol., 61, 4 (537-540), 2008

\section{HEMATOCELE CRÓNICO IMITANDO UN TUMOR TESTICULAR. PRESENTACIÓN DE DOS CASOS}

\section{Concepción Lara Bohorquez, Virginia Porras Hidalgo y Pilar Jurado Escamez.}

Servicio de Anatomía Patológica. Hospital Infanta Elena. Huelva. España.

Resumen.- OBJETIVO: El diagnóstico diferencial de masas escrotales incluye procesos inflamatorios, tumores malignos y lesiones traumáticas, incluyendo hematomas y hematocele crónico.

MÉTODOS/RESULTADOS: Presentamos dos casos de hematocele crónico discutiéndose las características clínicoradiológicas de dichas lesiones y su diagnóstico diferencial.

CONCLUSIONES: El diagnóstico preoperatorio de hematocele puede ser difícil, ya que la sintomatología puede imitar una lesión quística o una neoplasia.

Palabras clave: Hematocele. Masa testicular.
Concepción Lara Bohorquez

Servicio Anatomía Patológica

Hospital Infanta Elena

Ctra. Sevilla - Huelva s/n

21080 Hueva. (España)

clarab@andaluciajunta.es 